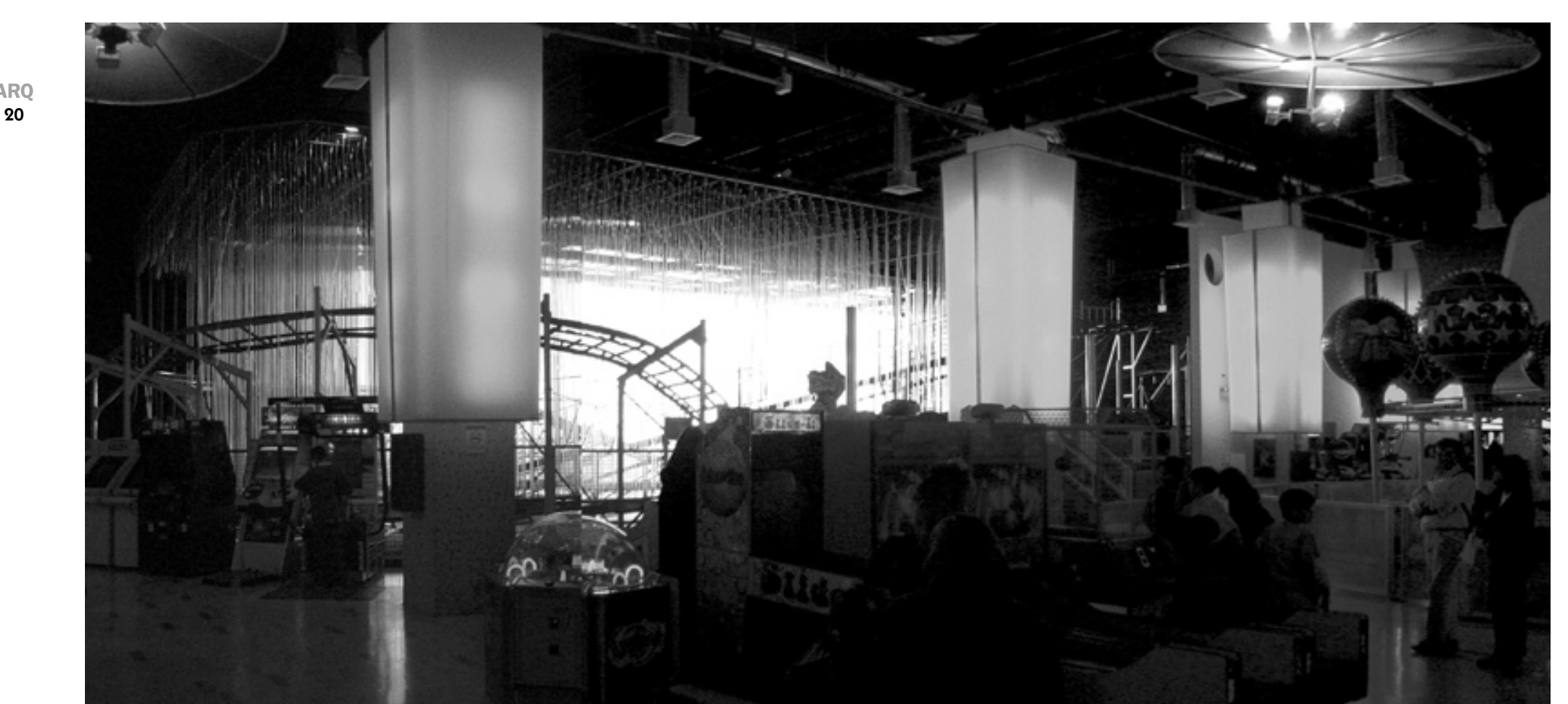

Mathias Klotz
Santiago, Chile

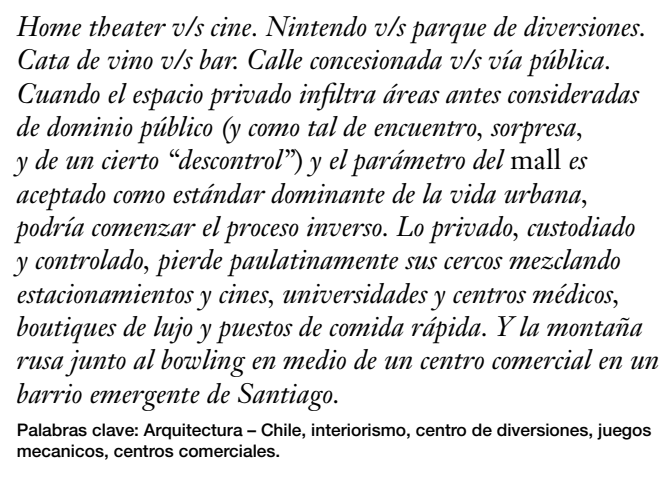

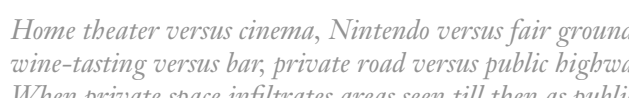

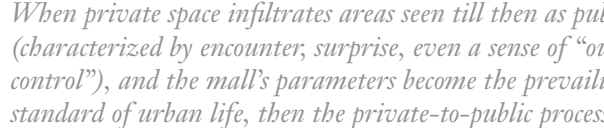

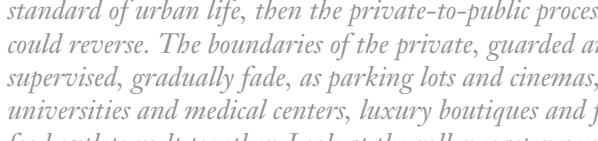

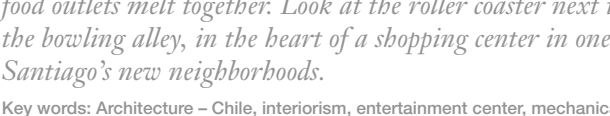

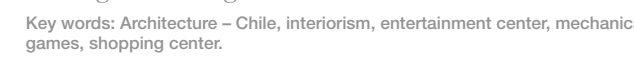

\section{Aventura Center}

Aventura Center es un proyecto que ganamos del espacio propuesto, transmitida a través del
través de un concurso privado. El encargo: cambio de imágenes en un ambiente dinámico. proyectar un centro de juegos para público tanto Apoyando esta idea, se han determinado tres Infantil como adolescente y adulto. El lugar sería tipos de iluminación: proyectores data sbow, luz El encargo hacía hincapié en la independencia de la Se pueden elegir motivos temáticos variados que $\begin{aligned} & \text { propuesta del paso de la moda. Esta condicionante } \\ & \text { se resuelve por lo generán los separando la responsables de modificar la percepción } \\ & \text { del espacio fácilmente, con los elementos que se }\end{aligned}$ de la decoración, la cual tematiza el interior; la consideren apropiados de acuerdo ala temporada. presencia de un tema fijo, difícil de cambiar, y que a la luna, tras la selección de las mejores fotos sólo sorprende la primera vez que se visita el lugar. de las misiones Apolo, veríamos en la zona del Propusimos transformar el lugar en espacio y acceso desde el patio de comidas la imagen de la sucesión de planos de proyección donde piso, Los elementos mopuestos para logra los objerios muro $y$ cielo se funden en un único elemento, descritosfueron: cieloymuros devolcanits continus. estableciendo distintos ámbitos para las actividades que se curvan y recortan para dar continuidad al que aqui se realizan. Los planos de proyección espacio; cielos de barrisol para enfatizar ciertas zonas, su color el lugar, apoyados por un sistema de La idea es tratar que la envolvente sea un soporte reflectores y proyectores que refuerzan los colores de color y de imágenes sin que compita visualmente predominantes de la temática en cuestión. con los juegos que alberga, ya que en este espacio $\begin{array}{lll}\text { De esta manera entendemos que Aventura Center } & \text { conviven todo tipo de dispositivos: carruseles, } \\ \text { puede ser un lugar de diversión y también algo } & \text { pistas de bowling, una montaña rusa y una pista de }\end{array}$ $\begin{array}{ll}\text { puede ser un lugar de diversión y también algo } & \text { pistas de bowling, una } \\ \text { más el factor añadido en este caso es la flexibilidad } & \text { patinaje en hielo. Aro }\end{array}$ un espacio interior de $4.313 \mathrm{~m} 2$, dentro del mall
Florida Center.
istirectas reflejada a reas (proyector y campana). son
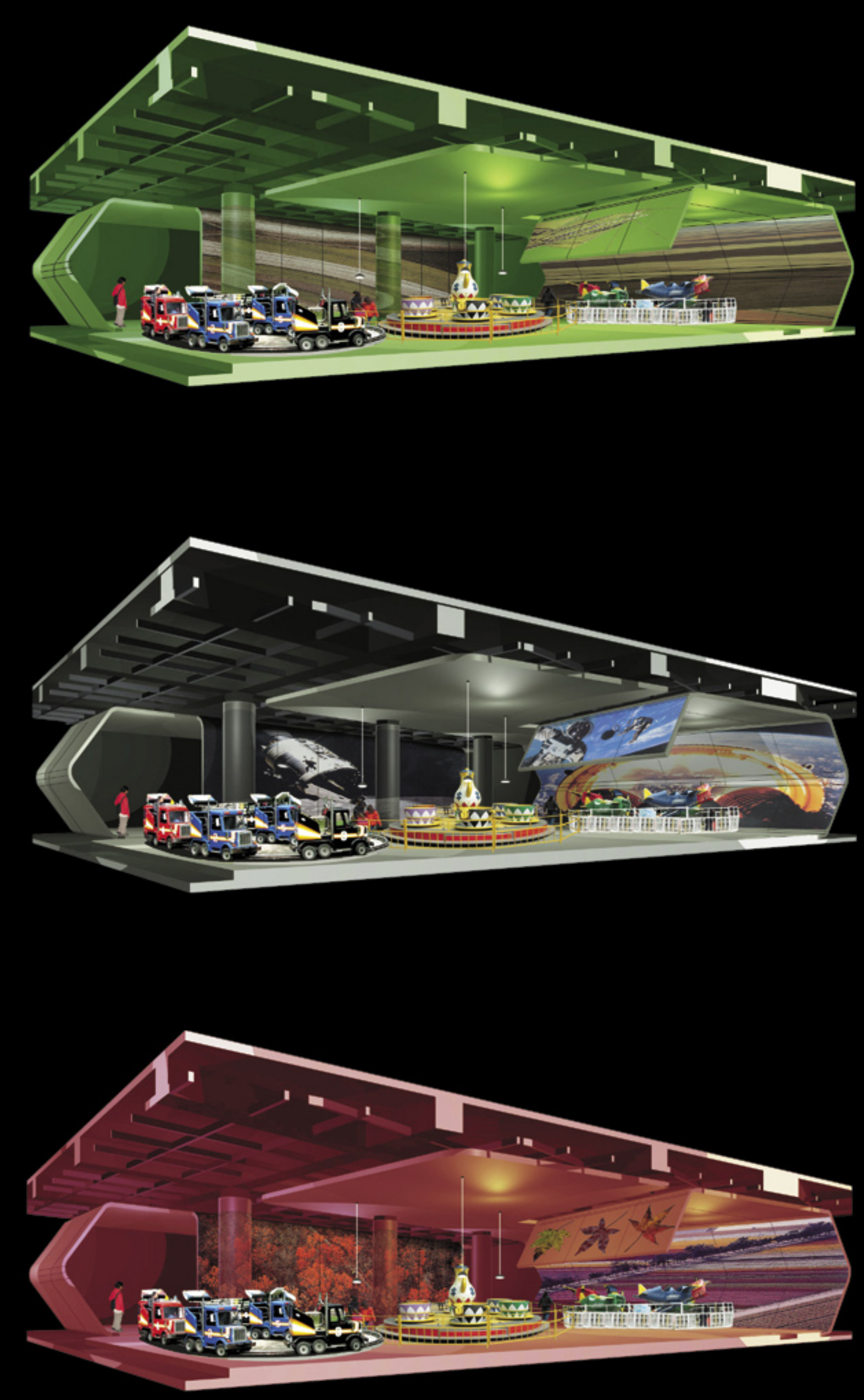
$\underset{22}{A R Q}$
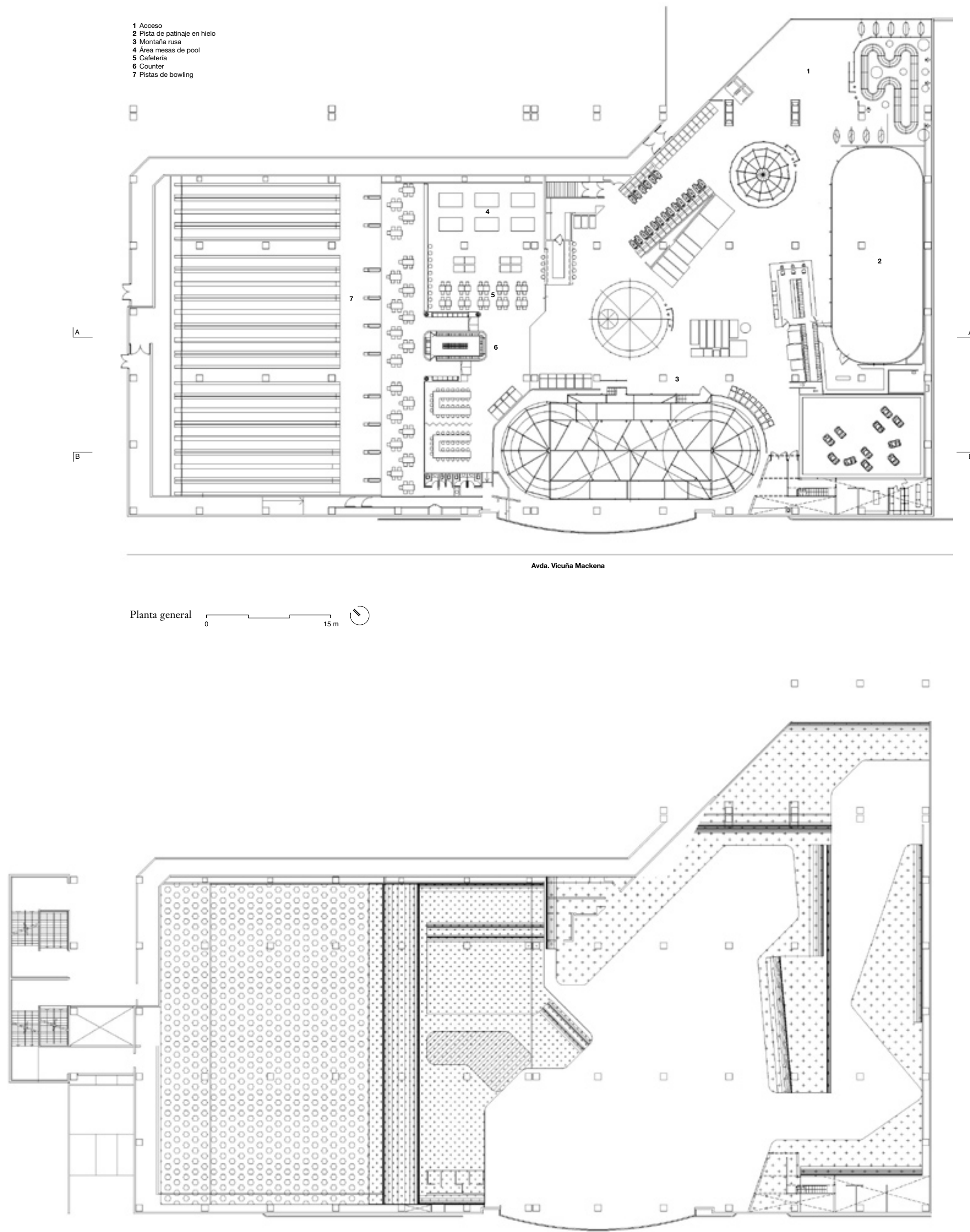
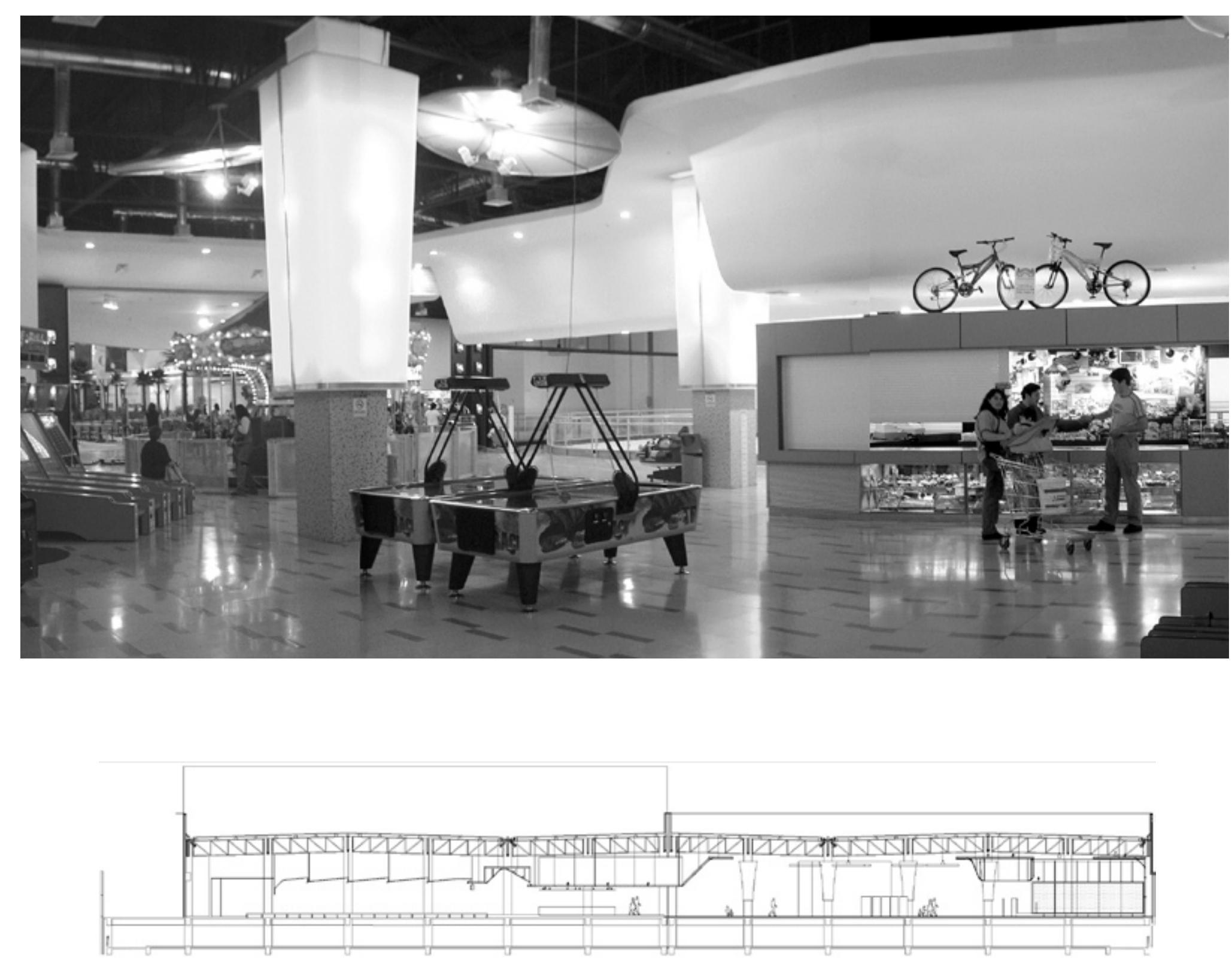

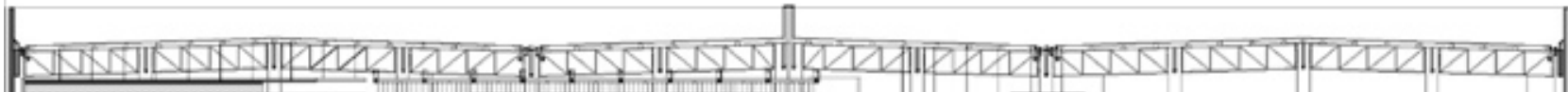

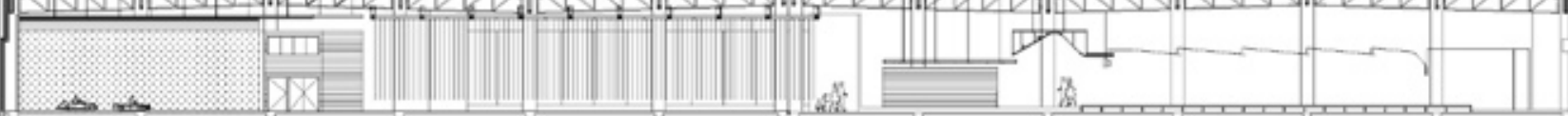


